\title{
O MESTRAdO PROFISSIONAL NO ÂMBITO dAS POLítICAS PÚBLICAS NA EDUCAÇÃO: REFLEX̃̃eS SOBRE \\ A PRODUÇÃO dO CONHECIMENTO CIENTíFICO
}

THE PROFESSIONAL MASTER COURSE IN THE SCOPE OF PUBLIC POLICIES IN EDUCATION: REFLECTIONS ON THE PRODUCTION OF SCIENTIFIC KNOWLEDGE El MÁSTER PROFESIONAL DENTRO DE LAS POLÍTICAS PÚBLICAS EN LA EDUCACIÓN: REFLEXIONES SOBRE LA PRODUCCIÓN DE CONOCIMIENTO CIENTÍFICO

\author{
Graziela Giacomazzo ${ }^{1}$ \\ Denise Leite ${ }^{2}$
}

\begin{abstract}
RESUM0: Este artigo aborda o ensino stricto sensu, especificamente o Mestrado Profissional (MP). Apresentase essa área de ensino a partir do seu contexto histórico, no âmbito dos estudos e análises que se ocupam em configurar o lugar dessa formação no ensino da pós-graduação no Brasil. Para tanto, consideram-se os acontecimentos que marcaram a sua criação e inserção no Brasil, identificando as políticas públicas na educação que contribuíram para a efetivação de sua legislação e abrangência. No intuito de posicionar o MP no ensino stricto sensu, analisam-se as avaliações realizadas pela Fundação Coordenação de Aperfeiçoamento de Pessoal do Ensino Superior (Capes), as quais indicam certo crescimento dos MP na pós-graduação, no Brasil, colocando esse nível de ensino em foco no cenário educacional. Posteriormente apresenta-se uma análise com base nas reflexões da(s) Ciência(s) no contexto "pós", especificamente, a Ciência Modo 2 e nos quesitos/critérios orientados para o Mestrado Profissional.
\end{abstract}

PALAVRAS-CHAVE: Políticas públicas. Mestrado profissional. Conhecimento científico.

\begin{abstract}
This paper discusses the stricto sensu graduate, specifically the Professional Master Course (MP). It presents teaching area from its historical context in the scope of studies and analysis that configures the place of the education in stricto sensu graduate in Brazil. Therefore, we consider the events that marked their creation and insertion in Brazil, identifying public policies in education that contributed to the effectiveness of their legislation and coverage. In order to position the MP in stricto sensu graduate in, we analyzes the evaluations performed by Fundação Coordenação de Aperfeiçoamento de Pessoal do Ensino Superior (CAPES), which indicate some growth in the MP Stricto Sensu graduate in Brazil, putting this level of education focus on the educational scene. Subsequently it presents an analysis based on the reflections of science in the context of Science Mode 2 and in items/ criteria oriented to Professional Master Course.
\end{abstract}

KEYWORDS: Public policy. Stricto Sensu professional master graduate. Scientific knowledge.

RESUMEN: Este artículo aborda la educación estricta, específicamente la Maestría Profesional (MP). Presenta esta área de enseñanza de su contexto histórico, el alcance de los estudios y análisis que trato establecido en su lugar dicha formación en la enseñanza del curso de postgrado en Brasil. Para ello, tenemos en cuenta los acontecimientos que dieron forma a su creación y la inserción en el Brasil, la identificación de las políticas

\footnotetext{
${ }^{1}$ Doutora. Universidade do Extremo Sul Catarinense. Docente/Pesquisadora. Criciúma - SC - Brasil. E-mail: gfg@unesc.net

${ }^{2}$ Doutora. Universidade Federal do Rio Grande do Sul. Docente/Pesquisadora. Porto Alegre - RS - Brasil. Email: denise.leite@ hotmail.com.br
}

Recebido em:14/11/2014 - Aceito em:17/12/2014

\begin{tabular}{l|l|l|l|l|l|l} 
(C) ETD - Educ. temat. digit. & Campinas, SP & v.16 & n.3 & p.475-493 & set./dez. 2014 & ISSN 1676-2592
\end{tabular}


públicas en materia de educación que contribuyeron a la eficacia y el alcance de su legislación. Con el fin de posicionar el sentido estricto de enseñanza en MP analiza las evaluaciones realizadas por la Fundação Coordenação de Aperfeiçoamento de Pessoal do Ensino Superior (CAPES), que indican un cierto crecimiento en el MP de postgrado en Brasil, poniendo de este nivel de la educación centrarse en la escena educativa. Posteriormente se presenta un análisis basado en las reflexiones de (s) Ciencia (s) en el contexto 'Post', especificamente Modo 2 de la Ciencia, en los criterios orientados en la Maestría Profesional.

PAlabRaS ClavE: Políticas públicas. Máster profesional. Conocimiento científico.

\title{
1 MESTRADO PROFISSIONAL NO BRASIL
}

O Mestrado Profissional é a modalidade que enfatiza uma formação voltada aos estudos e técnicas com alto nível de qualificação profissional, diferenciando-se em relação ao Mestrado Acadêmico. Não se trata de ensinar técnicas, mas de direcionar problemas específicos, encontrando soluções ou respostas em temas localizados ou em áreas em que se buscam soluções em contextos reais - no campo profissional e no contexto da Universidade.

O mestrado profissional constitui oportunidade de maior aproximação entre os trabalhos conduzidos pela universidade, às demandas - espontâneas ou induzidas pela própria universidade existentes no campo social e profissional, demandas por soluções tecnológicas, sociais e em geral, estruturadoras do conhecimento nas atividades profissionais. Apresenta uma dimensão voltada à horizontalidade e verticalização do conhecimento e assim vital para as atuais necessidades do Brasil. (QUELHAS; FARIA FILHO; FRANÇA, 2005, p. 98).

O Mestrado Profissional confere, pois, idênticos graus e prerrogativas, inclusive para o exercício da docência, e, como todo programa de pós-graduação stricto sensu tem a validade nacional do diploma condicionada ao reconhecimento prévio do curso; possibilita atuação em espaços diversificados, tanto públicos quanto privados em diferentes instituições profissionais.

\begin{abstract}
Esses profissionais possuem a mesma qualificação legal, por exemplo, para lecionar em instituições de ensino, sejam elas públicas ou privadas. Extrapolando-se essa questão legal, afirma-se que esses profissionais podem muito bem auxiliar em inúmeras outras esferas públicas que cooperem para a educação quando esta é percebida de maneira ampla, isto é, quando é percebida de forma plural e não exclusiva das escolas e universidades. A formação humana e cidadã de um profissional advindo de um curso de MP podem muito bem refletir-se em muitas instituições profissionais, inclusive instituições públicas e estatais, como prefeituras, hospitais, tribunais, escolas. (RIBEIRO, 2010, p. 443).
\end{abstract}

Trata-se, portanto, de um curso de mestrado dirigido a profissionais, com ênfase em conteúdos aplicados em atividades de pesquisa. O curso busca formar um profissional capacitado para pesquisa, desenvolvimento e inovação (P\&D\&I), capaz de atuar como multiplicador no seu campo profissional. (QUELHAS; FARIA FILHO; FRANÇA; 2005, p. 
98). A Portaria $n^{\circ} 7$, de 22 de junho de 2009, que dispõe sobre o Mestrado Profissional no âmbito da Capes, define-o e evidencia a atenção dada ao rigor cientifico e metodológico:

Art. $3^{\circ}$. O mestrado profissional é definido como modalidade de formação pósgraduada stricto sensu que possibilita:

I - a capacitação de pessoal para a prática profissional avançada e transformadora de procedimentos e processos aplicados, por meio da incorporação do método científico, habilitando o profissional para atuar em atividades técnico-científicas e de inovação;

II - a formação de profissionais qualificados pela apropriação e aplicação do conhecimento embasado no rigor metodológico e nos fundamentos científicos. (BRASIL, 2009).

A inserção do Mestrado Profissional (MP) no Brasil ocorreu no âmbito da pósgraduação (PG), estabelecendo-se no cenário educacional brasileiro a partir da década de 1960. Portanto, compreender como ocorreu essa inserção colabora para reconhecer o lugar do MP nesse nível de ensino.

O início da pós-graduação no Brasil e sua institucionalização aconteceram, precisamente, com o Parecer CES/CFE no 977/65, sendo estruturada entre cursos lato sensu (especialização) e stricto sensu (mestrado e doutorado). Naquele momento vivia-se sob o mandato do Regime Militar, cujo paradigma levou "a Pós-Graduação a assumir uma visão tecnicista, característica marcante dos governos de exceção, e marcadamente influenciada pelos modelos norte-americano e francês". (ESCOTT, 2012, p. 244). Ao contextualizar historicamente o início da PG no Brasil, Moreira e Velho (2008) descrevem-no como um modelo linear, inclinado para a concepção desenvolvimentista em que o país estava submerso.

No Brasil, a qualificação formal de pesquisadores foi impulsionada principalmente a partir da década de 60. Ações coordenadas pelo governo, com o apoio da comunidade científica iniciaram naquele período uma nova fase da educação superior brasileira. O modelo da PG brasileiro foi organizado em torno do paradigma do modelo linear de inovação, ou seja, baseado na ideia da ciência como uma 'fronteira sem fim', com a responsabilidade de impulsionar o desenvolvimento do país. (MOREIRA; VELHO, 2008, p. 630).

Posteriormente ao Parecer n 977/65 foram instituídos o I Plano Nacional de Pósgraduação - PNPG (1975-1977); o II PNPG (1982-1985); o III PNPG (1986-1989); o IV PNPG (década de 1990) — este Plano não se efetivou, mas suas diretrizes e instrumentos pautaram as ações da Capes de 1996 a 2004-; e o V PNPG (2005-2010). 
Em continuidade aos cinco anteriores, o PNPG (2011-2020), paralelo ao Plano Nacional de Educação (PNE), em que, "pela primeira vez, um plano nacional de educação contemplará as propostas de diretrizes e políticas do ensino de pós-graduação, isso porque o PNPG é parte integrante do PNE”. (BRASIL, 2010, p. 13).

Antes de situar o que está sendo prospectado no atual PNPG, vale lembrar que os PNPGs anteriores permitiram o desenvolvimento da pós-graduação e do sistema de ensino superior como um todo. A Capes, ao registrar a importância dos Planos que antecederam as reflexões para o PNPG (2011-2020), destaca como impulsionadoras da expansão as seguintes ações: integração da pós-graduação no interior do sistema universitário, institucionalizando a atividade de pesquisa em diversas instituições; aumento da capacitação do corpo docente do ensino superior, por meio de programas direcionados para essa finalidade; construção de um sistema de bolsas no país e no exterior; estruturação de uma política de apoio financeiro aos programas de pós-graduação; participação de representantes da comunidade acadêmica nos processos de formulação da política de pós-graduação; implantação de um sistema nacional de avaliação dos programas, realizado por meio de julgamento de pares; integração do ensino à pesquisa, estabelecendo-se um número limitado de disciplinas articuladas com as respectivas linhas de pesquisa dos cursos; fortalecimento da iniciação científica; criação de um sistema de orientação de dissertações e de teses; articulação da comunidade acadêmica nacional com centros da produção científica internacional. (BRASIL, 2010, p. 38-39).

O PNPG (2011-2020), em continuidade às ações implementadas nos Planos anteriores, prevê um futuro marcado por articulações mais fortes entre a academia e as competências requeridas no mundo do trabalho, ampliando os espaços de inovação, também organizados por modelos híbridos de ensino e pesquisa, suportados por altas tecnologias de informação e comunicação. Isso possibilita reinventar propostas pedagógicas orientadas para maior interação entre a prática profissional e a teoria, no âmbito da inter e da transdisciplinaridade. (FISCHER, 2010; ESCOTT, 2012).

A partir das configurações, aqui apresentadas, da PG, no Brasil, tem-se a implantação dos MP, em 1995, pela Portaria n 47, de 17 de outubro, conhecida como "Portaria Sucupira" em alusão ao relator Prof. Newton Sucupira. Essa portaria determinou a implantação, na Capes, de procedimentos apropriados à recomendação, acompanhamento e avaliação de cursos de mestrado dirigidos à formação profissional. 
O MP sofreu certa rejeição inicial em virtude de seu surgimento ocorrer no momento em que a academia brasileira vivenciava o impacto da expansão da educação superior no mercado. Essa expansão foi conduzida pelo próprio Ministério da Educação, de forma aligeirada. "As críticas, muitas vezes certeiras, sobre a nova forma de condução da Ciência no Brasil podem ser creditadas mais a essa mudança geral do que um receio aos MP em particular”. (RIBEIRO, 2010, p. 436).

Ao se analisar a implantação dos MP, Fischer (2010) considera as rejeições e as restrições sofridas próprias dos projetos desenvolvimentistas no Brasil. Exemplifica essa posição relembrando modalidades de formação profissional que foram rejeitadas inicialmente, por causa da ideia de ser o ensino profissional "mais pobre". A autora menciona os liceus de artes e ofícios, as escolas técnicas e escolas normais de formação de professores, por estes serem "[...] referências de qualidade de ensino não apenas cumprindo seu papel na formação de técnicos e professores como possibilitaram o acesso à formação científica em cursos de graduação e pós-graduação”. (FISCHER, 2010, p. 262).

Para Menandro (2010) o surgimento dos MPs não foi reflexo apenas de uma política desenvolvimentista, pois as restrições e reações negativas se relacionavam, naquele momento, à pouca expansão dos doutorados, valorizando-se, assim, os mestrados; ao início de uma avaliação mais técnica, com foco na produção publicada; ao crescimento das instituições privadas com pouca tradição em pesquisa, contratando muitos recém-aposentados das instituições públicas. Além disso, o prestígio da pós-graduação ainda assegurava um dos únicos territórios atingidos com menor impacto pelo descaso governamental com as universidades naquele momento. Por esses fatores, o autor considera, ainda, a prática acadêmica dos MP um enorme desafio para sua implementação nas instituições de ensino superior, e cada caso deve ser analisado de forma individualizada.

\footnotetext{
Aparentemente, todos esses fatores contribuíram para a reação de muitos dos docentes ligados à pós-graduação e à própria Capes, docentes entre os quais, por razões óbvias, predominava uma orientação estritamente acadêmica. Foi como se os Mestrados e Doutorados Acadêmicos dissessem ao inesperado intruso: Mestrado Profissional, você sabe com quem está falando? (MENANDRO, 2010, p. 369).
}

Sendo assim, muitos não concordaram com a implantação dos MPs, pois poderiam provocar uma redução do nível de exigências fazendo com que surgissem cursos de menor 
qualidade no país, prejudicando a internacionalização da pós-graduação. (MENANDRO, 2010).

A partir da Portaria Sucupira outras foram sendo criadas para legitimar e regulamentar os MPs, por exemplo, a Portaria $\mathrm{n}^{\circ}$ 80, de 16 de dezembro de 1998, que dispõe sobre o reconhecimento dos mestrados profissionais e dá outras providências, e recomenda a " $[. .$. utilização de critérios pertinentes a peculiaridades dos cursos que ela disciplina, destacando que a produção técnico-profissional decorrente de atividades de pesquisa, extensão e serviços prestados deverá ser especialmente valorizada". (ESCOTT, 2012, p. 252-253). Posteriormente, a regulamentação foi compreendida a partir da Portaria Normativa $n^{\circ} 17$, de 28 de dezembro de $2009^{1}$, no âmbito da Capes e com a Portaria Normativa $n^{\mathbf{o}} 289$, de 21 de março de 2011, que dispõe sobre a concessão de bolsas de formação para professores da rede pública matriculados em cursos de Mestrado Profissional. A partir da apresentação da sua regulamentação apresenta-se, a seguir, por meio dos dados estatísticos divulgados pela Capes, o lugar do MP na pós-graduação no Brasil.

\section{O LUGAR do MESTRAdo PROFisSiOnAL NA PóS-GRAdUAÇÃo}

Para situar o lugar do MP inicia-se com a relação numérica e a abrangência dos MPs, incluindo-se os dados conforme o Relatório de Divulgação dos Resultados da Avaliação Trienal 2010² dos Programas de Pós-graduação stricto sensu no Brasil.

A avaliação presencial ocorreu entre 19 de julho e 14 de agosto de 2011 e contou com a participação de 877 avaliadores com qualificação e competência técnico-científica nas suas respectivas áreas de conhecimento. Os avaliadores, organizados em 46 comissões de avaliação, analisaram os dados referentes ao período de 2007 a 2009, informados pelos 2.718 programas avaliados. Inicialmente verificou-se o número de discentes titulados no MP, conforme a Tabela 1 e a Tabela 2 a seguir:

TABELA 1 - Discentes Titulados pelos Programas de Pós-graduação Triênio 2007-2009

\begin{tabular}{l|c|c|c|c}
\hline \multicolumn{1}{c|}{ Nível/Ano } & $\mathbf{2 0 0 7}$ & $\mathbf{2 0 0 8}$ & $\mathbf{2 0 0 9}$ & Total \\
\hline Mestrado Acadêmico & 30.569 & 33.378 & 35.698 & 99.645 \\
\hline Doutorado & 9.919 & 10.718 & 11.368 & 32.005 \\
\hline Mestrado Profissional & 2.331 & 2.653 & 3.102 & 8.086 \\
\hline Total & 42.819 & 46.749 & 50.168 & 139.736 \\
\hline
\end{tabular}

Fonte: Capes (2011) 
TABELA 2 - Discentes Titulados pelos Programas de Pós-Graduação Triênio 2010-2012

\begin{tabular}{l|l|l|l|l}
\hline Nível/Ano & 2010 & 2011 & 2012 & Total \\
\hline Mestrado Acadêmico & 35.965 & 39.387 & 42.780 & 118.132 \\
\hline Doutorado & 11.210 & 12.267 & 13.879 & 37.356 \\
\hline Mestrado Profissional & 3.236 & 3.591 & 4.252 & 11.079 \\
\hline Total & 50.411 & 55.245 & 60.910 & 166.566 \\
\hline
\end{tabular}

Fonte: Adaptado de Capes (2013)

Percebe-se um aumento de discentes titulados em programas de MP, contudo, há enorme distanciamento em relação aos titulados em Mestrados Acadêmicos (MA). Os resultados revelam a história "bipolar" da pós-graduação entre o eixo profissional e o eixo acadêmico, as diferenças e rejeições, e a falta de credibilidade e estímulos em relação à educação profissional no Brasil, que se mostra incipiente, com territórios a serem explorados, vivenciados e melhor avaliados. No dizer de Fischer (2010) precisamos reencontrar o 'elo perdido', neste caso, a Educação profissional.

Os dados mostram não apenas o distanciamento, mas a separação entre os dois eixos: acadêmico e profissional, e tem sido alvo de debates entre os analistas e estudiosos da pósgraduação brasileira. Os que apoiam o MP defendem que esse não deve ser encarado apenas como uma opção, mas como um recurso estratégico mobilizador para se repensar a pósgraduação do século XXI, “[...] que será um sistema de fluxos articulados entre si e com outros níveis de ensino, que vai incorporar a tecnologia quebrando as barreiras entre o chamado ensino presencial e o ensino a distância”. (FISCHER, 2010, p. 266).

Em relação à quantidade de cursos oferecidos na modalidade MP, apresenta-se a tabela a partir de 1998. “O grande aumento no número de cursos de mestrados profissionais a partir de 1998 implica forte crescimento nas previsões para os próximos três anos, com um aumento de aproximadamente 35\% do valor de 2011 para 2013.” (BRASIL, 2010, p. 80).

TABELA 3 - Número de cursos de pós-graduação: Ano/Nível

\begin{tabular}{c|c|c|c|c}
\hline \multirow{2}{*}{ ANO } & \multicolumn{4}{|c}{ NÍVEL } \\
\hline & DOUTORADO & $\begin{array}{c}\text { MESTRADO } \\
\text { PROFISSONAL }\end{array}$ & MESTRADO & TOTAL \\
\hline 1998 & 779 & 27 & 1463 & 2269 \\
\hline 1999 & 846 & 69 & 1563 & 2478 \\
\hline 2000 & 903 & 98 & 1620 & 2621 \\
\hline
\end{tabular}




\begin{tabular}{c|c|c|c|c}
\hline 2001 & 940 & 138 & 1689 & 2767 \\
\hline 2002 & 984 & 158 & 1758 & 2900 \\
\hline 2003 & 1015 & 175 & 1796 & 2986 \\
\hline 2004 & 1048 & 190 & 1955 & 3093 \\
\hline 2005 & 1099 & 202 & 2096 & 3224 \\
\hline 2006 & 1195 & 174 & 2242 & 3714 \\
\hline 2007 & 1269 & 203 & 2337 & 3897 \\
\hline 2008 & 1327 & 233 & 2587 & 4397 \\
\hline 2009 & 1532 & 278 & 2771 & 4757 \\
\hline 2010 & 1630 & 356 & & \\
\hline
\end{tabular}

Fonte: Adaptado de Brasil $^{3}$ (2010, p. 80)

Esse crescimento, considerado significativo, impulsionou um grupo de professores a constituírem, em 2006, o Fórum Nacional dos Mestrados Profissionais (FOPROF), "visando um diálogo permanente entre os coordenadores dos mestrados profissionais do país e os representantes da Capes e da sociedade civil organizada" (FOPROF, 2013). As ações do FOPROF são propositivas e avaliativas, ocorrem periodicamente, com o intuito de estabelecer a excelência e a sustentabilidade dessa nova modalidade de mestrado da pósgraduação brasileira. As atuais ações políticas desse fórum articulam-se por meio do "Movimento Nacional em Defesa do MP nas IES Públicas", integrando a Comissão de Constituição e Justiça e de Cidadania; a Comissão de Educação; e a Comissão de Finanças e Tributação.

Conforme o Regimento Interno do Fórum Nacional dos Mestrados Profissionais participam, na condição de membros "natos", os Coordenadores dos Programas de Mestrado Profissional das instituições públicas e particulares brasileiras, em exercício de mandato.

\begin{abstract}
Art. $1^{\circ}$, O Fórum Nacional dos Mestrados Profissionais - FOPROF é uma entidade de caráter permanente voltada para articulação e proposição de políticas acadêmicas, tecnológicas, de inovação e de inserção social, comprometida com a formação de profissionais para o desenvolvimento de novas tecnologias e aperfeiçoamento de processos e produtos, contribuindo para a capacidade técnica e cientifica, bem como para o atendimento às demandas geradas pelo mundo do trabalho. (FOPROF, 2013).
\end{abstract}

O FOPROF, por sua atuação, pode ser considerado um indicativo importante para aferir a abrangência do MP no Brasil, além de refletir, avaliar e propor ações que qualificam esse nível de ensino. A preocupação e os temas que são debatidos nos encontros dizem 
respeito à educação profissional no Brasil, nas dimensões educativa, política, sociológica, entre outras.

Ainda em relação à abrangência e à expansão, os cursos de MP estão sendo ofertados em diversas áreas do conhecimento, contudo, as de maior número, de acordo com as estatísticas, são a área Multidisciplinar, com 19,5\%, e a área das Ciências da Saúde, com 18,5\%. As de menor oferta, até o momento, são Linguística, Letras e Artes, com 1,89\%, e Ciências Biológicas, com 3,3\%, entre as que oferecem o MP. Há maior índice nas instituições públicas, com $65,7 \%$ do total das ofertas.

Em relação à avaliação dos cursos, de acordo com as estatísticas, capturadas em novembro de 2013, no portal Capes, dos MP, a maioria, ou seja, 433 estão classificados com o conceito 3, apenas 31 apresentam conceito 5. A avaliação dos MP também tem sido alvo de debates, acertos, críticas, diferenciações e comparações com o MA. “[...] É importante lembrar que um dos pontos mais incisivos da reação ao Mestrado Profissional sempre foi a dificuldade de estabelecimento de critérios para avaliá-lo”. (MENANDRO, 2010, p. 369).

A avaliação dos MPs responde igualmente aos critérios e determinações do Sistema de Avaliação da Pós-graduação no Brasil, tanto na avaliação dos Programas quanto na avaliação das Propostas de Cursos Novos. Os parâmetros de regulação e avaliação dos MPs foram definidos, inicialmente, pela Portaria $n^{\circ}$ 47/1995, a partir das seguintes dimensões: Instituição; Docentes e Orientadores; Financiamento; e Currículo, este último subdividido em Estrutura Curricular; Ensino e Pesquisa; e Trabalho Final. Para Escott (2012) essa proposta de avaliação centrava-se fortemente na titulação e produção intelectual, ampliando, em alguns aspectos, a produção intelectual por meio da valorização de outras produções técnicas. Também possibilitava outros formatos para as dissertações, um corpo docente com atuação parcial e reconhecida qualificação profissional e a sustentabilidade financeira. Esse último também alvo de inúmeras críticas pelas dificuldades de natureza política e jurídica que as instituições públicas encontram para o autofinanciamento.

Em documento ${ }^{4}$ elaborado, em 2011, pelo FOPROF as reflexões e proposições para sua avaliação e sustentabilidade indicavam os seguintes desafios a serem enfrentados pelos MP: a falta de adesão do mundo do trabalho aos Mestrados Profissionais; a elaboração de um modelo de financiamento dos Mestrados Profissionais nas IES públicas; fomento aos 
Mestrados Profissionais por intermédio da articulação dos governos federal, estaduais e municipais em algumas áreas estratégicas; aperfeiçoamento da Avaliação da Capes dos Mestrados Profissionais; avaliação ser realizada pelos pares com experiência em Mestrados Profissionais.

Pelas exigências naturais do próprio contexto histórico dos MPs e impulsionados pelas análises que emergiram da Portaria $n^{\circ} 47$, no triênio 2007-2009, a Capes organizou nova ficha de avaliação ${ }^{5}$, a qual está em vigor, conforme o Quadro 1, a seguir.

QUADRO 1 - Ficha de avaliação do Mestrado Profissional/Triênio 2007-2009.

\begin{tabular}{|c|c|}
\hline QUESITOS & CRITÉRIOS \\
\hline \multirow{5}{*}{$\begin{array}{l}\text { QUESITO I - } \\
\text { PROPOSTA DO } \\
\text { CURSO } \\
\text { Peso mínimo de } 10 \% \\
\text { para todos os itens }\end{array}$} & $\begin{array}{l}\text { Coerência, consistência, abrangência e atualização da(s) área(s) de concentração, } \\
\text { linha(s) de atuação, projetos em andamento, proposta curricular com os objetivos } \\
\text { do Curso/Programa e da modalidade Mestrado Profissional. }\end{array}$ \\
\hline & $\begin{array}{l}\text { Coerência, consistência e abrangência dos mecanismos de interação efetiva com } \\
\text { outras instituições, atendendo demandas sociais, organizacionais ou profissionais. }\end{array}$ \\
\hline & Infraestrutura para ensino, pesquisa e extensão. \\
\hline & $\begin{array}{l}\text { Planejamento do Curso/Programa visando ao atendimento de demandas atuais ou } \\
\text { futuras de desenvolvimento nacional, regional ou local, por meio da formação de } \\
\text { profissionais capacitados para a solução de problemas e geração de inovação. }\end{array}$ \\
\hline & $\begin{array}{l}\text { Articulação do Curso/Programa de Mestrado Profissional com cursos acadêmicos } \\
\text { do mesmo Programa de Pós-graduação. }\end{array}$ \\
\hline \multirow{3}{*}{$\begin{array}{l}\text { QUESITO II - } \\
\text { CORPO DOCENTE } \\
\text { Faixa de variação de } \\
\text { peso: de } 15 \% \text { a } 20 \%\end{array}$} & $\begin{array}{l}\text { Perfil do corpo docente, considerando-se experiência como profissional e/ou } \\
\text { pesquisador, titulação e sua adequação à Proposta do Curso/Programa e à } \\
\text { modalidade Mestrado Profissional. }\end{array}$ \\
\hline & $\begin{array}{l}\text { Adequação da dimensão, composição e dedicação dos docentes permanentes para o } \\
\text { desenvolvimento das atividades de pesquisa e formação do Curso/Programa. }\end{array}$ \\
\hline & $\begin{array}{l}\text { Distribuição das atividades de pesquisa, projetos de desenvolvimento e inovação e } \\
\text { de formação entre os docentes do Curso/Programa. }\end{array}$ \\
\hline \multirow{2}{*}{$\begin{array}{l}\text { QUESITO III - } \\
\text { CORPO DISCENTE E } \\
\text { TRABALHOS DE } \\
\text { CONCLUSÃO }\end{array}$} & $\begin{array}{l}\text { Quantidade de trabalhos de conclusão aprovados no período de avaliação e sua } \\
\text { distribuição em relação ao corpo docente. }\end{array}$ \\
\hline & $\begin{array}{l}\text { Qualidade dos Trabalhos de Conclusão e produção cientifica, técnica ou artística } \\
\text { dos discentes e egressos. }\end{array}$ \\
\hline $\begin{array}{l}\text { Faixa de Varia } \\
\text { Peso: de } 25 \% \text { a }\end{array}$ & Impacto dos Trabalhos de Conclusão e da atuação profissional do egresso. \\
\hline \multirow{4}{*}{$\begin{array}{l}\text { QUESITO IV - } \\
\text { PRODUÇÃO } \\
\text { INTELECTUAL E } \\
\text { PROFISSIONAL } \\
\text { DESTACADA } \\
\text { Faixa de Variação de } \\
\text { Peso: de } 30 \% \text { a } 35 \%\end{array}$} & Publicações do Curso/Programa por docente permanente. \\
\hline & Produção técnica, patentes e outras produções consideradas relevantes. \\
\hline & Produção artística, nas áreas em que tal tipo de produção for pertinente. \\
\hline & $\begin{array}{l}\text { Vínculo entre Produção técnica e Publicações qualificadas do } \\
\text { Curso/Programa. }\end{array}$ \\
\hline \multirow[t]{3}{*}{$\begin{array}{l}\text { QUESITO V - } \\
\text { INSERÇÃO SOCIAL } \\
\text { Faixa de Variação de } \\
\text { Peso: de } 20 \% \text { a } 25 \%\end{array}$} & $\begin{array}{l}\text { Impacto do Programa: a) Impacto social; c) Impacto tecnológico; d) Impacto } \\
\text { econômico; e) Impacto sanitário; f) Impacto cultural; g) Impacto artístico; h) } \\
\text { Impacto profissional; i) Impacto legal; j) Outros impactos considerados pertinentes } \\
\text { pela Área. }\end{array}$ \\
\hline & $\begin{array}{l}\begin{array}{l}\text { Integração e cooperação com outros } \\
\text { desenvolvimento da pós-graduação. }\end{array} \\
\text { desos/Programas }\end{array}$ \\
\hline & \\
\hline
\end{tabular}




\begin{tabular}{|l|l|}
\hline \multirow{y}{*}{} & $\begin{array}{l}\text { área de conhecimento do Curso/Programa, visando ao desenvolvimento de novas } \\
\text { soluções, práticas, produtos ou serviços nos ambientes profissional e/ou acadêmico. }\end{array}$ \\
\cline { 2 - 2 } & Divulgação e transparência das atividades e da atuação do Curso/Programa. \\
\cline { 2 - 3 } & Percepção dos impactos pelos egressos e/ou organizações/instituições beneficiadas. \\
\hline & $\begin{array}{l}\text { Articulação do MP com outros Cursos/Programas ministrados pela Instituição na } \\
\text { mesma área de atuação. }\end{array}$ \\
\hline
\end{tabular}

Fonte: Brasil (2010)

Ao se analisar a faixa de variação de peso fica evidente que a maior ênfase (peso) recai sobre o Quesito IV - Produção Intelectual e Profissional Destacada e seus respectivos critérios, que incluem diferentes formas de produção. Entretanto, outros aspectos que compõem a identidade e natureza dos MPs são relevantes. Neste estudo, considerando-se o interesse da pesquisa, serão destacados os quesitos e critérios que mais se aproximam dos princípios do Modo 2 de produção do conhecimento científico, os quais serão tratados a seguir.

\section{MESTRADO PROFISSIONAL E A CIÊNCIA MODO 2}

O Mestrado Profissional possui uma natureza mais exógena, e estabelece, portanto, maiores relações extramuros, seguindo a lógica da produção do conhecimento compartilhado, aplicado a problemas reais. Conforme estabelece o Quesito V, sua inserção é avaliada por meio de diferentes formas de impactos. Esses fatores aliados aos demais que o caracterizam, se relacionam fortemente com os princípios do Modo 2 de produção do conhecimento estudados por Gibbons et al. (1994,1997).

Ribeiro (2010, p. 439), ao analisar a condição endógena das pesquisas acadêmicas, reporta-se à metáfora da "Torre", em que a universidade é considerada uma instituição fechada:

[...] essa consideração é condensada na conhecida expressão "torre de marfim" e, de certa forma, é referendada por muitas práticas acadêmicas. Em contrapartida, há outro discurso que afirma que a integração da universidade à sociedade se faria sob o manto do utilitarismo, isto é, a universidade deveria servir à sociedade; essa postura também é referendada por aqueles que consideram ser a função primordial, senão única, do ensino universitário produzir agentes para o mercado. Esses dois argumentos formam um falso paradoxo, pois partem do princípio de que há uma relação desigual e apartada entre a universidade e a sociedade.

Ambos, MA e MP, buscam produzir uma mesma resposta, em que a universidade é parte integrante da sociedade, na qual não apenas se reflete, mas produz reflexão. Portanto, segundo Ribeiro (2010, p. 441), "o senso comum de que os mestrados profissionais seriam

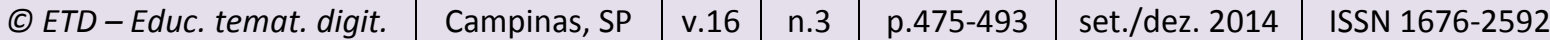


instrumentos que exclusivamente promovem a transformação da educação universitária em mercadoria é, no mínimo, um erro histórico". A criação desses cursos pode ser uma das possibilidades de (re)alinhamento das relações entre a universidade e a sociedade em uma perspectiva de compartilhamento e cooperação, estreitando seus processos e objetivos às finalidades sociais mais emergentes. Para tanto, a universidade, ao se dispor a abrir espaços aos novos modos de formação profissional, poderá ampliar suas relações com a sociedade.

[...] A criação de um novo modelo de pós-graduação pode servir, pelo contrário, como uma forma de transformação na direção de outras competências e contribuições sociais que se mostrem capazes de negar a suposta naturalidade de características tanto do indivíduo como do conjunto de seus participantes, substituindo, por exemplo, competitividade por cooperação coletiva. (RIBEIRO, 2010, p. 441).

O Mestrado Profissional, nos cenários futuros, pelos números apresentados, ainda deverá percorrer um longo caminho para inserir-se mais efetivamente nas instituições, o que implica, também, formas inovadoras de avaliação. O desafio está posto e a inserção desses novos cursos merece ser analisada tanto pela academia quanto pela sociedade, de forma criteriosa, em conformidade com as determinações da Capes, contudo, há outros elementos teóricos disponíveis e que podem ser considerados nessa tarefa. Em paralelo ao debate do MP há novos modos de produção do conhecimento que também sugerem maior interação entre universidade e sociedade, como o Modo 2.

Os contornos desse Novo Modo de Produção do Conhecimento, denominado Modo 2, são observados e estudados por Michael Gibbons ${ }^{6}$ e seus colaboradores. Os autores são pesquisadores de instituições da Inglaterra, Canadá, Austrália, Brasil e Estados Unidos. As ideias publicadas nas respectivas obras conquistaram grande importância no meio acadêmico e político, atraindo a atenção de pesquisadores e gestores, conforme constatou Buedo e Vielba (2009) ao abordarem as mudanças mais recentes na pesquisa científica e tecnológica, por meio de diferentes correntes de pensamento, entre elas o Modo 2.

Na obra revista e publicada em 2001, os autores, diante das críticas recebidas pela ausência de estudos empíricos, esclarecem que, nas duas publicações (1994; 2001), os escritos são ensaios de reflexão que buscam oferecer uma análise detalhada das tendências descritas respectivamente. Diante disso, tem-se que o Modo 2 de conhecimento serve ao 
propósito de contrastar com o Modo 1, cuja pesquisa científica realiza-se de forma disciplinar, homogênea e hierárquica, assim definida por Buedo e Vielba (2009, p.722):

És decir, la producción de conocimiento se realiza en organizaciones jerárquicas permanentes (universidades y centros de investigación) con el objetivo de avanzar en el conocimiento de la realidad para satisfacer los propios intereses académicos y disciplinarios.

Segundo Gibbons (1998), a estrutura disciplinar do Modo 1 desempenha papel central na gestão e na organização das universidades na atualidade, o que as tornam as principais legitimadoras dessa forma de produção do conhecimento, considerando-se a estrutura disciplinar, seja em ciências, ciências sociais, ou ciências humanas. Esse modelo também organiza o ensino nas universidades, delineando os currículos de graduação. Assim, a estrutura disciplinar é o elo essencial que liga ensino e pesquisa e que sustenta o argumento de que, nas universidades, eles estão perfeitamente adequados e indissociáveis. Nesse sentido, a pesquisa não apenas contribui para o estoque de conhecimento especializado, mas também para transformá-lo. Nas palavras de Gibbons ${ }^{7}$ (1998, p.5),

\begin{abstract}
esta estrutura fornece as diretrizes para pesquisadores sobre quais são os problemas importantes a serem investigados, como devem ser enfrentados, quem deve enfrentá-los e o que deve ser considerado como contribuições importantes para o campo. Resumindo, a estrutura disciplinar define tanto o que é "boa ciência" e prescreve, também, o que os alunos precisam saber se quiserem se tornar cientistas.
\end{abstract}

Para os autores, o Modo 2, no futuro, mudará a forma com que as universidades têm exercido a docência e a pesquisa, além de proporcionar critérios que redefinirão a sua relevância. (Gibbons et al, 1994). Essas mudanças estão diretamente relacionadas às mudanças sociais, políticas e econômicas no contexto mundial de globalização, acrescidas da evolução e abrangência exponencial das tecnologias de informação e comunicação.

Em suas análises, Gibbons (1998, p. 6) define os seguintes atributos para especificar as características do Modo 1 e do Modo 2: a dinâmica do Modo 2 centra-se, principalmente, no livre fluxo de informações e na comunicação aberta entre diferentes áreas do conhecimento e diferentes setores da sociedade, em múltiplas direções - eletrônica, organizacional e socialmente relevantes; no Modo 1, os problemas são definidos e resolvidos em um contexto regido (grande parte acadêmico) pelos interesses de uma comunidade específica. Por outro lado, no Modo 2, o conhecimento é produzido em um contexto de aplicação. O Modo 1 é disciplinar, homogêneo, organizacionalmente hierárquico e tende a 
preservar sua estrutura; já o Modo 2 é transdisciplinar, heterogêneo e estruturalmente transitório. Os dois possuem formas distintas de controle de qualidade, sendo que o Modo 2 é mais responsável socialmente e, assim, mais reflexivo. (Gibbons, et al., 1997, p.14).

A título de ilustração, no quadro a seguir apresentam-se algumas características entre o Modo 1 e o Modo 2 de produção do conhecimento científico, na definição e solução de problemas; no campo da pesquisa; na organização, na difusão dos resultados, nas formas de financiamento, nos resultados e impacto social, na qualidade destes.

Apresenta-se, portanto, uma análise para identificar características entre o MP e o M2 a partir dos princípios de produção do conhecimento Modo 2 de Gibbons et al $(1994,1997)$ e dos quesitos/critérios que compõem a Ficha de Avaliação do MP - Capes. Assim, busca-se colaborar e contribuir com as reflexões que estão em curso sobre o MP no Brasil. Para tanto, organizou-se um quadro com os seguintes princípios do M2: aplicabilidade, heterogeneidade e reflexividade e com os respectivos conceitos para o M2 e MP.

QUADRO 2 - Mestrado Profissional e Modo 2

\begin{tabular}{|c|c|c|}
\hline PRINCÍPIOS & MODO 2 (M2) & MESTRADO PROFISSIONAL (MP) \\
\hline APLICABILIDADE & $\begin{array}{l}\text { Produção do conhecimento no } \\
\text { contexto da aplicação, em uma base } \\
\text { de consulta de diferentes interesses. } \\
\text { A aplicabilidade se refere ao } \\
\text { estabelecimento de compromissos } \\
\text { sólidos entre o conhecimento } \\
\text { aplicado e sua finalidade social, em } \\
\text { um contexto real. }\end{array}$ & $\begin{array}{l}\text { Formação de profissionais para a solução } \\
\text { de problemas e geração de inovação. } \\
\text { Integração e cooperação com } \\
\text { organizações ou instituições, visando ao } \\
\text { desenvolvimento de soluções, práticas, } \\
\text { produto, serviços no ambiente } \\
\text { profissional ou acadêmico. Produção } \\
\text { técnica, patentes e outras produções } \\
\text { relevantes. }\end{array}$ \\
\hline HETEROGENEIDADE & $\begin{array}{l}\text { Caracteriza-se pela heterogeneidade } \\
\text { e diversidade organizacional. É } \\
\text { heterogêneo em torno das } \\
\text { habilidades e experiências dos } \\
\text { sujeitos envolvidos. A interação } \\
\text { entre os diferentes atores ocorre em } \\
\text { múltiplas direções: eletrônica, } \\
\text { organizacional e socialmente por } \\
\text { meio de redes de colaboração. }\end{array}$ & $\begin{array}{l}\text { Caracteriza-se } \\
\text { consistência e pela abrangência dos } \\
\text { mecanismos de interação efetiva com } \\
\text { outras instituições, atendendo demandas } \\
\text { sociais, organizacionais ou profissionais. } \\
\text { Integração e cooperação com outros } \\
\text { Cursos/Programas visando a } \\
\text { desenvolvimento da pós-graduação. }\end{array}$ \\
\hline REFLEXIVIDADE & 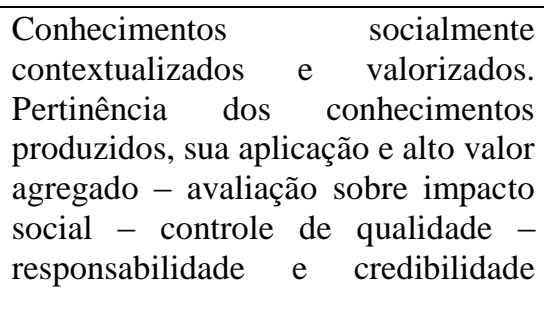 & $\begin{array}{l}\text { Impacto dos Trabalhos de Conclusão e } \\
\text { da atuação profissional do egresso. } \\
\text { Divulgação e transparência das } \\
\text { atividades e da atuação do Curso/ } \\
\text { Programa. Avaliação por meio da } \\
\text { percepção dos impactos pelos egressos } \\
\text { ou organizações/ instituições } \\
\text { beneficiadas. Análise do Impacto social; }\end{array}$ \\
\hline
\end{tabular}




\begin{tabular}{|l|l|l|}
\hline & social. & $\begin{array}{l}\text { Impacto tecnológico; Impacto } \\
\text { econômico; Impacto sanitário; Impacto } \\
\text { cultural; Impacto artístico; Impacto } \\
\text { profissional; Impacto legal; outros } \\
\text { impactos pertinentes. }\end{array}$ \\
\hline
\end{tabular}

Fonte: Autoras

Percebe-se, pelo quadro comparativo, que há consideráveis relações e proximidades conceituais entre o MP e o M2. No que diz respeito à aplicabilidade, ambos buscam o contexto da aplicação em situações localizadas, visando à solução de problemas reais e a geração de resultados por meio de produtos. Nas orientações encontradas para cada quesito, na Ficha de Avaliação dos MPs - Capes, encontra-se uma grande lista de possíveis produtos que, de modo geral, são: prestação de serviço; desenvolvimento de material didático e instrucional; desenvolvimento de produto; desenvolvimento de técnica ou processo; elaboração de projeto; patentes; divulgação técnica; outro tipo de produção técnica. Este último tópico é relevante no sentido de resgatar uma das características do MP relacionada ao atendimento da demanda da sociedade. Outro aspecto encontrado na orientação para o MP em relação ao princípio da aplicabilidade são as perspectivas que o Curso/Programa deve estabelecer para o seu desenvolvimento futuro, contemplando os desafios da área na produção e aplicação do conhecimento, suas metas quanto à inserção social e profissional.

A aproximação ao princípio da heterogeneidade entre o M2 e o MP ocorre pela exigência de ambos em relação à abrangência, cooperação, integração e à efetiva interação com outras instituições. No MP, a inserção e a interação com o respectivo setor externo/social é indispensável no caso de um Curso/Programa profissional, e deve produzir resultados relevantes que possam ser objetivamente descritos e apreciados. Mesmo no âmbito do próprio programa, o MP demanda articulação entre o Curso/Programa de Mestrado Profissional com os demais cursos acadêmicos que integram o Programa de Pós-graduação; deve possibilitar a participação em programas de cooperação e intercâmbio sistemáticos com outros, na mesma área, na modalidade Mestrado Profissional, e a participação em projetos de cooperação entre Cursos/Programas com níveis de consolidação diferentes, voltados para a inovação em pesquisa, o desenvolvimento da pós-graduação ou o desenvolvimento econômico, tecnológico e/ou social, particularmente em locais com menor capacitação científica ou tecnológica. Também se espera a participação em convênios ou programas de cooperação com organizações/instituições setoriais voltados para a inovação na pesquisa; o avanço da pós-graduação ou o desenvolvimento tecnológico, econômico e/ou social no \begin{tabular}{l|l|l|l|l|l|l} 
(C) ETD - Educ. temat. digit. & Campinas, SP & v.16 & n.3 & p.475-493 & set./dez. 2014 & ISSN 1676-2592 \\
\hline
\end{tabular} 
respectivo setor ou região, e a introdução de novos produtos ou serviços (educacionais, tecnológicos, diagnósticos, etc.), no âmbito do Curso/Programa, que contribuam para o desenvolvimento local, regional e nacional.

O princípio da reflexividade é amplo nos dois casos e se mostra evidente também em ambos. No MP é quase imprescindível que todo trabalho gere aplicação dos seus resultados na respectiva organização em que atua o mestrando. Deve, também, ser informado o impacto que a aplicação produziu na organização, recomendando-se fortemente a utilização de indicadores quantitativos. A aplicação pode ocorrer antes, logo depois ou algum tempo após a defesa, mas é relevante existir a intenção de aplicação por parte da organização.

\section{CONSIDERAÇÕES FINAIS}

Todas as características que foram identificadas até aqui também se encontram de forma pontual no M2, sendo que a aplicabilidade também pode ocorrer em todo o processo, de diferentes formas, em diferentes lugares e equipes envolvidas. As informações no MP exigidas pela Capes sobre esses resultados/produtos incluem a apresentação de um resumo objetivo, destacando em que condições ele foi aplicado. Tais resumos não podem ter a forma genérica e vaga de dizer que foram examinados, discutidos. Deve ser expresso com clareza qual o diagnóstico do problema e quais as soluções apontadas, se foram ou não implementadas, por que e com que resultados.

A reflexividade implica fortemente o estudo do impacto existente de forma impositiva tanto no M2 quanto no MP. No MP, esse estudo aparece organizado por vários tipos de impactos e busca avaliar se a formação de recursos humanos qualificados para a sociedade contribui para o desenvolvimento das pessoas envolvidas em projetos das organizações públicas ou privadas e no Brasil. A inserção e a interação com o respectivo setor externo/social é indispensável no caso de um Curso/Programa profissional e deve produzir resultados relevantes que possam ser objetivamente descritos e apreciados.

As tendências e indicadores de prospecção lançados pelo Plano Nacional de Pósgraduação (PNPG) 2011-2020 orientam para muitas das noções de produção do conhecimento elencadas no Modo 2 e reforçam o que já está sendo avaliado no Mestrado Profissional. Ao abordar o tema avaliação Escott (2012, p. 260) conclui que a efetiva 
consolidação da Pós-graduação sricto sensu, no contexto brasileiro, ocorrerá na ressignificação das relações entre "a universidade e o mundo do trabalho, valorizando a inserção e o diálogo com os profissionais que atuam diretamente nas diversas áreas e valorizando a produção técnico-profissional aplicada, além da produção científica ou a ela relacionada".

As alterações na política Científica e Tecnológica (C\&T) do país, ao longo dessas cinco décadas, decorrem das mudanças na concepção dos modos de produção do conhecimento científico e tecnológico ao longo da história, alterando, também, a organização nas atividades de pesquisa, nos instrumentos, processos e procedimentos utilizados nas instituições na PG. "Isso tem gerado um grande grau de incerteza sobre os caminhos mais adequados para planejar, conduzir e avaliar as atividades científicas e tecnológicas". (MOREIRA e VELHO, 2008, p. 626).

\footnotetext{
É necessário que os novos paradigmas da Ciência e tecnologia sejam colocados na pauta das discussões sobre o modelo mais adequado para a pós-graduação brasileira, seja por iniciativa da Capes, tanto quanto por iniciativa dos que atuam na gestão dos cursos em todo o país. (MOREIRA; VELHO, 2008, p. 642).
}

Diante das relações entre MP e M2 apresentadas, conhecer modos de produção alinhados às expectativas nacionais para o futuro da PG no Brasil torna-se uma ferramenta de reflexão e análise nas mãos dos profissionais que decidem sobre os cursos nesse nível de ensino nas instituições. Como orienta Moreira e Velho (2008), as políticas relativas à formação de recursos humanos demandam revisão no seu desenho e nos critérios e formas de avaliação.

\section{REFERÊNCIAS}

BRASIL. Conselho Federal de Educação. Parecer CES/CFE n 977/65, de 3 de dezembro de 1965. Dispõe sobre a definição dos cursos de pós-graduação. Brasília, DF: MEC, 1965.

BRASIL. Ministério da Educação. Fundação Coordenação de Aperfeiçoamento de Pessoal de Nível Superior. Plano Nacional de Pós-Graduação - PNPG 2011-2020. Brasília, DF: CAPES, 2010. v.2.

BRASIL. Ministério da Educação.Portaria no 80, de 16 de dezembro de 1998. Dispõe sobre o reconhecimento dos mestrados profissionais e dá outras providências. Diário Oficial da União, Brasília, DF, 1998. 
BRASIL. Ministério da Educação. Portaria $n^{\circ}$ 7, de 22 de Junho de 2009. Dispõe sobre o mestrado profissional no âmbito da Fundação Coordenação de Aperfeiçoamento de Pessoal de Nível Superior - Capes. Diário Oficial da União, Brasília, DF, 2009.

BRASIL. Ministério da Educação. Portaria n 289, de 21 de Março de 2011. Dispõe sobre a concessão de bolsas de formação para professores da rede pública matriculados em cursos de Mestrado Profissional. Diário Oficial da União, Brasília, DF, 2011.

BRASIL. Ministério da Educação. Ficha de avaliação dos mestrados profissionais: triênio 2007-2009. Brasília: CAPES, 2010. Disponível em: <http://trienal.capes.gov.br/wpcontent/uploads/2010/07/regulamento-para-a-avalia\%c3\%87\%c3\%83o-09jul10.pdf > Acessado em: 6 mar. 2013.

BRASIL. Ministério da Educação. Portaria no 47 de 17 de outubro de 1995. Programa de flexibilização do modelo de pós-graduação senso estrito em nível de mestrado. Brasília: CAPES, 1995. Disponível em: <http://www2.capes.gov.br/rbpg/images/stories/downloads/ RBPG/vol.2_4_jul2005_/Documentos_Artigo4_n4.pdf> Acessado em: 6 mar 2013.

BUEDO, María Jiménez-; VIELBA, Irene Ramos. Más allá de la ciencia académica? : modo2, ciencia posacadémica y ciencia posnormal. Revista Arbor Ciencia, Pensamiento y Cultura, Madri, v.185, n.738, p.721-737, jul /ago 2009.

ESCOTT, Clarice Monteiro. Avaliação e Produção do Conhecimento nos Mestrados profissionais. In: LEITE, Denise; LIMA, Elizeth Gonzaga dos Santos. Conhecimento, avaliação e redes de colaboração: produção e produtividade na universidade. Porto Alegre: Sulina, 2012. p.244-245.

FISCHER, Tania. Proposiçoes sobre Educação Profissional em Nível de Pós_Graduação para o PNPG 2011-2020. In: BRASIL, Ministério da Educação. Fundação Coordenaçao de Aperfeiçoamento de Pessoal de Nível Superior. Plano nacional de Pó-Graduação - PNPG 2011/2020. Brasília, DF: CAPES, 2010. v.2.

FISCHER, Tânia. Seduções e riscos: a experiência do mestrado profissional. Revista de admministração de empresas, São Paulo, SP, v.43, n.2, p. 119-123, apr/jun 2003.

FOPROF. Regimento Interno do Fórum Nacional dos Mestrados Profissionais. Fórum Nacional dos Mestrados Profissionais. Disponível em: <http://www.foprof.org.br> Acesso em: 20 jan 2013.

GIBBONS, Michael et al. The new production of knowledge - the dynamics of science and research in contemporary societies. London: Thousand Oaks; California: Sage Publications, 1994.

GIBBONS, Michael et al.. La nueva producción del conocimiento: la dinámica de la ciencia y la investigación en las sociedades contemporáneas. Tradução de José M. Pomares. Barcelona: Ediciones Pomares-Corredor S.A, 1997. Disponível em: <http://www. schwartzman.org.br/sitesimon/?page_id=546\&lang=pt-br> Acesso em: 1 out 2012. 
GIBBONS, Michael. Higher education in the 21st Century. In: CONFERENCE ON HIGHER EDUCATION, 1998, Paris. Final repport... Paris: Unesco, 1998. Disponível em:

$<$ http://www.unesco.org/new/en/education/themes/strengthening-education-systems/highereducation/reform-and-innovation/1998-world-conference/> Acesso em: 8 ago 2011.

MENANDRO, Paulo Rogério Meira. Réplica 2: mestrado profissional, você sabe com quem está falando?. Revista de Administração Contemporânea, Curitiba, v. 14, n. 2, p. 367-371, abr 2010 .

MOREIRA, Maria Lígia; VELHO, Lea. Pós-graduação no Brasil: da concepção "ofertista linear" para "novos modos de produção do conhecimento" Implicações para avaliação.

Revista da Avaliação da Educação Superior, Sorocaba, v. 13, n. 3, p. 625-645, nov 2008.

QUELHAS, Osvaldo Luiz Gonçalves; FARIA FILHO, José Rodrigues; FRANÇA, Sergio Luiz Braga. O mestrado profissional no contexto do sistema de pós-graduação brasileiro.

Revista Brasileira de Pós-Graduação, Brasília, v.2, n.4, p.97-104, jul 2005.

RIBEIRO, Cláudio Rezende. A universidade como disputa da reprodução social: contribuição ao debate sobre os mestrados profissionais. Revista Brasileira de Pós-Graduação, Brasília, DF, v. 7, n. 14, p. 433 - 450, dez 2010.

\footnotetext{
${ }^{1}$ Esta portaria revogou a publicada em 22 de junho de 2009.

${ }^{2}$ Dados disponíveis em: http://www.capes.gov.br.

${ }^{3}$ A tabela foi atualizada em 23/02/2011 (BRASIL, 2010).

${ }^{4}$ Documento aprovado na Assembleia Ordinária do FOPROF em Florianópolis, 9 de novembro de 2011.

${ }^{5}$ Modelo de Ficha Aprovado 104 ${ }^{\text {a }}$ Reunião do CTC-ES em outubro de 2008.

${ }^{6}$ São duas as obras principais: The Dynamics of science new production of knowledge: the dynamics of science and research in contemporary societies (1994), cujos autores são Michael Gibbons; Martin Trow; Peter Scott; Simon Schwartzman; Helga Nowotny e Camille Limoges. E a obra intitulada Re-thinking science: Knowledge and the public in an age of uncertainty (2001), sob a autoria de Helga Nowotny; Peter Scott e Michael Gibbons. ${ }^{7}$ Traduzido pela autora.
}

\section{Como citar este documente:}

GIACOMAZZO, Graziela Fatima; LEITE, Denise Balarine Cavalheiro. O mestrado profissional no âmbito das políticas públicas na educação: reflexões sobre a produção do conhecimento científico. ETD - Educação Temática Digital, Campinas, SP, v. 16, n. 3, p. 475-493, set./dez. 2014. ISSN 1676-2592. Disponível em: <http://www.fe.unicamp.br/revistas/ged/etd/article/view/6888>. Acesso em: 23 dez. 2014. 